TALBOTT, Strobe \& CHANDA, Nayan (orgs.). 2002. A era do terror : o mundo depois de 11 de setembro. Rio de Janeiro : Campus.

\title{
ESTADOS UNIDOS: A DIFÍCIL ESCOLHA
}

\author{
Rafael Duarte Villa \\ Universidade de São Paulo
}

As relações internacionais no novo milênio não poderiam ter-se iniciado de uma forma mais dramática. Se dramático foi o ano de 1989 com a queda do muro de Berlim, a história repetiu-se mais uma vez, e não como farsa, mas como uma grande tragédia.

A dimensão da tragédia é tanto maior porque, ao atacar-se dois dos mais importantes símbolos do poder americano, obriga-se a uma reorganização de idéias que pareciam escamoteadas pela versão triunfalista ocidental que decorreu de sua vitória inegável sobre a União Soviética e sua forma de organização socialista. De alguma forma os Estados Unidos levaram muito a sério, nos últimos dez anos, a hipótese do cientista político Francis Fukuyama sobre o fim da história com a conversão de todos os povos, mais cedo ou mais tarde, à democracia liberal e seus valores individualistas e de pluralismo político. A "superpotência solitária", como chamou-a Samuel Huntington, intelectual do establishment americano, passou a comportar-se como se de fato a história houvesse acabado. Foi um incrível erro de avaliação política idealista para um país de tão acentuada tradição pragmática. A "dura réplica da história", veiculada através do mais selvagem massacre de milhares de vidas inocentes, não só permite desmentir Fukuyama, como também permite diagnosticar algumas implicações do que será nos próximos anos uma nova etapa da política internacional contemporânea.

Deixemos claro, antes de tudo, que os Estados Unidos continuam sendo o ator político mais relevante das relações internacionais durante o presente milênio devido à sua capacidade de ação global, decorrente de sua natureza como única superpotência multidimensional nos campos diplomático, militar, econômico e cultural. Longe de presenciarmos o declínio americano continuaremos a assistir ao fortalecimento de seu poderio mundial nas próximas décadas. Mas esse fortalecimento não se dará sem uma avaliação das implicações do ato terrorista do 11 de setembro de 2001, tanto na ordem política interna como na condução da política externa americana. O livro compilado por Talbott e Chanda, A era do terror, propõe-se a cumprir esse objetivo. Entretanto, digamos assim, é uma obra desigual. Não desigual no aspecto do conteúdo, mas na medida em que apresenta um bloco de artigos de importante conteúdo analítico misturado com outro bloco de artigos entre os quais se destacam artigos de conteúdo normativo (feito por conselheiros do príncipe), de duvidoso valor acadêmico. É do primeiro bloco que se ocupa este comentário e nele destacam-se os ensaios de historiadores da Universidade de Yale como John Lewis Gaddis, "E essa agora: lições da antiga era para a próxima"; de Paul Kennedy, "A recuperação do poder americano: da ferida à recuperação"; de Abbas Amanat, "O poder pela violência: a reinvenção do extremismo islâmico", e o artigo da historiadora Niall Fergunson da Universidade de Oxford, "O choque das civilizações, ou os mulás enlouqueceram: os Estados Unidos entre o império informal e o formal". Também será considerado o ensaio do especialista em estudos de segurança internacional Charles Hill, também de Yale, e que leva por título: "Uma tarefa hercúlea: mito e realidade do terrorismo árabe".

A hipótese comercial do livro, vendida pelos editores, é "que o imperdoável não deixa de ser compreensível e explicável". No entanto, o problema real para o qual atentam vários do ensaios são duas questões menos abstratas e mais diretas; a primeira é: em que falharam os Estados Unidos no 11 de setembro e qual é o futuro da superpotência? A segunda questão é: o Islã constitui mesmo um desafio político à hegemonia americana no século XXI? Como pode-se notar, não constituem problemas de grande originalidade, porém, sem dúvida, os autores sugerem respostas senão originais, ao menos bastante densas e interessantes.

O ensaio de Gaddis estrutura-se na base de um paradoxo: "O mais surpreendente no 11 de setembro foi a eficácia com que os terroristas lograram transformar objetos que nunca havíamos considerado perigosos em armas de potência letal [...]. Os terroristas também combinaram a crença (que talvez nos pareça primitiva) nas recompensas do martírio com os mais avançados métodos de planejamento, coordenação e execução. O que enfrentamos, pois, é não só uma nova categoria de armamentos de fácil obtenção como uma nova combinação 
de competências e de vontade de aplicá-las" (p. 26). Essa idéia leva Gaddis a formular a tese de que o poder militar americano não é mais suficiente para garantir sua segurança interna. É essa uma descoberta surpreendente para um país que, como os Estados Unidos, colocaram grande ênfase nas políticas de segurança internacional nos anos da Guerra Fria. Ou eles descuidaram-se de sua segurança interna, ou a vitória na Guerra Fria diante de seu inimigo global (a URSS) elevou-lhe tanto a autoconfiança que sua classe política perdeu a noção de que poderiam surgir outros inimigos - não necessariamente globais, mas igualmente letais, mesmo que sua ideologia não fosse tão sedutora e planetária quanto o cosmopolitismo democrático liberal.

Mas existe também uma outra questão de fundo para a qual o ensaio de Gaddis não atenta: a ironia do atentado terrorista é que os Estados Unidos nos últimos cinqüenta anos preparam-se no nível tecnológico nuclear mais sofisticado prevendo o ataque de um inimigo global territorial-estatal. Esses ataques poderiam vir dos soviéticos, chineses ou dos chamados estados delinqüentes (rogue states), como costumam-se chamar, desde a administração Clinton, países hostis como Líbia, Síria, Cuba, Iraque, Irã, Iraque, Sudão ou Coréia do Norte. Tais ataques não aconteceram e, provavelmente, não acontecerão. Entretanto, o que menos podiam prever os Estados Unidos é que ataques, que Samuel Huntington poderia denominar com justa razão de civilizacionais, viriam do nível não-estatal, originando-se de simples indivíduos armados de facas, estiletes e canivetes, e com uma eficácia estarrecedora.

Essa mesma constatação leva a outra conseqüência: as relações públicas da administração Bush encarregaram-se de vender a idéia amplamente divulgada pela mídia de que os Estados Unidos estavam em "guerra contra o terror". Para o despreparado staff de ideólogos que hoje comanda a política externa americana usar a expressão guerra ${ }^{1}$ sem contextualizar o que se quer dizer com isso talvez não faça muita diferença; mas ao atentarmos para o ator para o qual se estava declarando a guerra as implicações conceituais e estratégicas são evidentes. Como anotam na "Introdução" da $A$ era do terror, "Essa expressão parecia inadequada. Sempre havíamos pensado na guerra em termos de uma disputa civil dentro de uma nação ou de uma violência sistemática cometida por um Estado ou aliança contra outro" (p. 10). Aliás, a lógica da guerra (civil ou entre estados) foi sempre lembrada, desde os tempos imemoriais de Sun Tzu até chegar a seu mais eminente teórico Clausewitz: a vitória e o desarme do inimigo são os objetivos da guerra, mas não a destruição do inimigo. A descoberta da arma atômica encarregou-se de aprofundar ainda mais essa idéia na intelligentzia estatal. Como podiam os principais atores do sistema internacional enfrentarem-se em uma guerra da qual todos resultariam destruídos? O ataque aos Estados Unidos desconstrói certamente esse axioma civilizatório e humanista da teoria da guerra. Por isso estão certos Talbott e Chanda quando avançam a idéia de que "Com esse inimigo era diferente. A organização de Osama Bin Laden, a Al-Qaeda, não hasteou nenhuma bandeira - era a ONG fundamental - e seus guerreiros pareciam inspirados, não dissuadidos, pela perspectiva de suas próprias mortes causticantes" (p. 10-11).

No entanto essas reflexões em torno da guerra não resolvem a questão sobre em que os Estados Unidos falharam. Gaddis parece responder a essa questão qualitativa atentando para a conduta da política externa americana caracterizada pela atitude arrogante no pós-Guerra Fria. Os Estados Unidos recolhem o fruto de mais de uma década de unilateralismo pós-Guerra Fria. Embora as instituições e a cultura americana fossem reconhecidas e desejadas por uma boa parte do mundo, considera Gaddis que suas "políticas começaram a parecer despóticas, auto-indulgentes e insensíveis com relação aos interesses alheios" (p. 29). Marca patenteada desse unilateralismo foi que as relações com grandes potências como a China e a Rússia foram descuidadas e a promoção da democracia e dos direitos humanos fez-se de maneira desigual no âmbito regional. O mesmo comportamento repetiu-se frente à negociação dos regimes internacionais de baixa política (lembremos o Protocolo de Kyoto ou a negativa em ratificar o Tribunal Criminal Internacional), tratados com soberba, e também quanto ao sistema econômico globalista liberal, que passou a ser encarado como o único e secular caminho para atingir o progresso material e o fortalecimento das instituições políticas democráticas.

Certamente podemos concordar em que se trataram de erros com os quais o staff de Washington não se defrontou seriamente na última década. Mas a questão de fundo é a seguinte: os Estados Unidos poderiam ter

\footnotetext{
${ }^{1}$ Aliás, o Congresso americano autorizou o Presidente dos Estados Unidos a responder à agressão, mas não o uso de sua atribuição constitucional de declarar a guerra, de maneira que, formalmente, os Estados Unidos só responderam a "uma ameaça incomum e extraordinária à segurança nacional e à política externa americana", de acordo com a Resolução do Uso da Força aprovada pelo Congresso americano.
} 
agido de uma outra maneira? Poderiam ter trocado o unilateralismo por uma atitude de hegemonia benevolente que reconhecesse seu status de primus inter pares e que convencesse os outros grandes atores estatais do sistema internacional das vantagens para todos de sua hegemonia mundial ou pax americana? Daí que a resposta seja mais complexa, porque explicar o unilateralismo americano implica reconhecer que, de fato, houve erros na condução da política externa nesse período, mas também houve necessidades e escolhas das quais os Estados Unidos não se podiam furtar. Tome-se o exemplo dos bombardeios da Organização do Tratado do Atlântico Norte (OTAN) à Iugoslávia no ano de 1999: se, como ensina o realismo, nenhum Estado tem compromissos éticos nem imperativos morais com os cidadãos de outros estados, não haveria motivo para que a coalizão da OTAN encabeçada pela superpotência americana fosse em socorro da etnia albanesa muçulmana que estava sendo massacrada pelas hostes de Milosevic. Além disso, ao não consultar a Organização das Nações Unidas (ONU), a ação aparecia não só como unilateral mas também como ilegítima, principalmente porque violava o princípio de não-intervenção nos assuntos de outro Estado.

A conseqüência disso foi um desgaste e distanciamento com Moscou e Pequim, que também têm seus kosovos na Chechênia e no Tibete. Mas os Estados Unidos podiam agir de outra maneira, tinham outras escolhas? Na verdade foi o preço que tiveram que pagar por ter assumido o papel de polícia do mundo desde a Guerra do Golfo de 1991. Não se podia formular e dirigir uma nova ordem mundial (para utilizar as palavras pomposas de George Bush pai) sem receber esse ônus. Era o preço a pagar por uma tradição da política externa americana que reaparece de maneira cíclica, e tensiona os seus formuladores: a crença de que uma ordem internacional deve contemplar entre suas regras de good governance internacional a promoção dos direitos humanos. No entanto, a promoção dos direitos humanos não é o problema; ele aparece quando a política de direitos humanos é elevada à categoria de política estratégica. Esse foi o erro de Carter na década de 70. E fundamentalmente o erro consiste em que essa política de promoção da democracia e dos direitos humanos é globalmente incoerente, conclui Gaddis - com o que concordamos plenamente. Como justificar uma intervenção no Kosovo por motivos humanitários quando na Palestina, em Ruanda, na Chechênia e no Tibete milhares de pessoas morriam sem que os Estados Unidos fossem além das ações e declarações protocolares dos portavozes da Casa Branca? Raciocinando de novo do ponto de vista realista, diríamos que é praxe nas relações internacionais que os estados ajam seletivamente. Entretanto, "Uma coisa é atacar as bases terroristas e regimes brutais a título de punição. Outra, muito diferente, é o policiamento imperialista pela democracia: em termos políticos, provoca divisões e, em última instância, é um elemento debilitador - e, portanto, contrário a uma estratégia razoável para a manutenção do poder norte-americano no século XXI” (p. 89).

Em outras palavras, os Estados Unidos não são um Robinson Crusoé. É um ator internacional que interage com outros e que não deveria esquecer que a coerência de seu apostolado é funcional a médio e longo prazos para convencer seus aliados e parceiros estratégicos de ocasião da idéia de que o que é bom para o interesse nacional norte-americano acaba sendo benéfico para os seus também. Quer dizer, ajuda a sustentar a idéia de Adam Smith de que o egoísmo individual soma muito para a felicidade de todos.

A credibilidade nos propósitos de suas ações parece muito mais importante para os Estados Unidos a partir do 11 de setembro, sobretudo para convencer seus aliados e parceiros estratégicos de ocasião de que "O que vem emergindo é a perspectiva, mais uma vez, de 'algo pior' que um mundo dominado pelos americanos” (p. 35). Quiçá o elemento mais importante que emerge desses acontecimentos é a idéia de que é possível identificar um novo inimigo global, o terrorismo (o "algo pior"), em substituição aos velhos ismos de capitalismo e socialismo que polarizaram o mundo durante a Guerra Fria. Torna-se consensual para os três principais atores políticos do sistema internacional - antes divididos por questões ideológicas (Estados Unidos, China e Rússia) -, a identificação do terrorismo como o inimigo comum. Para os Estados Unidos as razões dessa identificação são óbvias. Já a Rússia pensa na Chechênia muçulmana e a China também tem problemas com grupos muçulmanos no oeste de seu território. Tanto a Rússia como a China instrumentalizam o discurso e são free-riders (caronas) do drama americano. Coloca-se então na agenda internacional a questão do chamado "pacto antiterrorista". Porém, é bem possível que uma questão dividirá e fragilizará essa aliança antiterror: qual é o fórum apropriado para tratar-se dessa matéria, assim como qual é o fórum apropriado para deliberar sobre retaliações no caso do atentado contra os Estados Unidos ou no caso de futuros atentados terroristas: a OTAN ou a ONU? Trata-se do problema de legalidade e legitimidade das futuras retaliações a grupos terroristas ou mesmo a outros estados. É claro que os Estados Unidos preferem como fórum deliberativo dessas questões a OTAN, consolidando o papel dessa organização como policial do mundo, modalidade que vem exercendo com relativo sucesso desde a Guerra do Golfo e dos bombardeios ao Kosovo. Por outro lado, é evidente que China e Rússia preferem que essa discussão se encaminhe na ONU, pelo poder de veto de que 
dispõem no Conselho de Segurança da ONU. Mas uma coisa parece estar clara: a ausência de qualquer desses três atores do pacto antiterrorista limitará e enfraquecerá a sua eficácia internacional.

De outro lado, isso obriga os Estados Unidos a contarem com aliados incômodos, como nos tempos da Guerra Fria, quando apoiavam regimes autoritários que eram funcionais a sua hegemonia. É uma preocupação que não escapa a outro ensaísta da $A$ era do terror, Paul Kennedy: "Agora, a identificação das redes terroristas como o maior inimigo da América e a aceitação de todos os governos que ajudem a esmagá-las podem criar um critério dúbio e contraproducente para a diplomacia a longo prazo. Grandes potências que impõem maus-tratos a suas minorias étnicas e religiosas - a Rússia na Chêchenia e a China no Tibete e em Xinjianang - podem ser indultadas, ou pelo menos seus atos podem ser ignorados. Países que eram vistos com desagrado e desconfiança - basta pensar no homicida regime sudanês - talvez sejam recompensados caso se posicionem contra o terrorismo internacional" (p. 87-88).

Kennedy reconhece, baseando-se no historiador inglês Sir Beloff, que toda aliança "implica servidões". Porém, o que parece passar estranhamente inadvertido ao sempre lúcido Kennedy é que essa política de "servidão" funcional já vem sendo aplicada faz algum tempo pelos Estados Unidos em relação à Rússia e à China. No caso desta última, a promoção desigual da justiça (leia-se "direitos humanos") é muito relativizada pela prioridade que adquire a entrada dos capitais e do comércio americano no imenso mercado chinês, assim como da entrada da China na Organização Mundial do Comércio. E também em relação aos regimes autoritários muçulmanos, não é de data recente que os Estados Unidos fazem vista grossa ao financiamento que a Casa dos Saud na Arábia faz de grupos fundamentalistas no Orienta Médio, Paquistão e Ásia Central, e que apostolam a versão fundamentalista sunita do Islã nessas regiões.

Kennedy também apresenta outra instigante questão, que serve para balizar a discussão em torno da segurança nacional dos Estados Unidos: "Como a maior economia de todas conseguirá manter suas vantagens relativas frente às demais nações, por décadas a fio, ao mesmo tempo em que convida o restante do planeta a reproduzir e imitar seus métodos e êxitos?" (p. 83). Essa pergunta não é formulada por acaso pelo autor. Há de se lembrar que Kennedy redigiu nos final dos anos 80 a polêmica obra Ascensão e queda das grandes potências (KENNEDY, 1989) obra na qual vaticinava o declínio americano, no longo prazo, pelo overstrech (sobrecarga) que seus gastos globais em defesa e armamento produziriam na sua economia. Certamente Kennedy é mais cauteloso que naquela época, mas mesmo assim não deixa de observar que as forças da globalização e da modernização constituem uma faca de dois gumes para os Estados Unidos, e que as conseqüências de ambos ainda não foram avaliadas adequadamente, nem pela liderança americana nem pelo grande público.

A questão torna-se mais dramática porque não existe independência entre as variáveis política e econômica. A globalização liderada pelos Estados Unidos supõe a venda de um modelo aberto de economia mundial que tem suas implicações para a segurança nacional do país. Assim, Kennedy une-se ao coro daqueles que lamentam o fato de que a consolidação de uma sociedade aberta (aos capitais, aos imigrantes, às idéias) e democrática criaram, por sua vez, as condições para que seja agredido por inimigos assimétricos "inteligentes e determinados". Daí que talvez a questão central que se coloca para o futuro americano seja a seguinte: como atingir um equilíbrio razoável entre fronteiras abertas e segurança nacional? Esse é um equilíbrio difícil de atingir na medida em que a globalização promovida pelos Estados Unidos não é percebida no exterior como um processo mais amplo, produto de uma dinâmica secular de modernização, mas como um reforço do próprio unilateralismo americano. Assim, se o objetivo de modernização não fosse atingido nos países não-ocidentais, "é muito provável que os Estados Unidos, suas empresas e cidadãos sejam culpados pelos custos sociais e políticos da integração econômica" (p. 82).

Ora, uma questão que se apresenta como central para esse eixo segurança-fronteiras abertas é algo que tem pouco a ver com os inimigos externos, e muito com a própria sociedade americana: como reverter a tendência que vem acentuando-se na opinião pública americana, de seletividade nas operações militares no exterior. Kennedy nota assim que se vem acentuando uma "má vontade da democracia americana para aceitar baixas militares em quantidades elevadas ou mesmo moderadas, durante anos ou décadas seguidas" (p. 76). O dilema é que atingir o equilíbrio segurança-globalização significará também que os Estados Unidos não se poderão furtar de intervir militarmente em teatros de operações externas a seu território nacional. Mas está cada vez mais claro (como aconteceu no conflito do Kosovo) que a sociedade americana nega-se a sacrificar a vida de seus filhos em operações militares nas quais não esteja claro qual é e de que maneira está em jogo o interesse nacional americano em termos de segurança nacional. 
Pode-se argumentar que essa é uma tendência que se consolida devido ao trauma decorrente da derrota no Vietnã, do insucesso no resgate dos reféns em Teerã no governo Carter ou da fracassada tentativa de invasão da Somália em 1993 (na qual morreram 18 soldados americanos). No entanto, é isso também um produto daquilo que Tocqueville chamava do "irresistível processo democrático". Mesmo uma instância como as corporações diplomáticas tendem a democratizar-se desconcentrando a responsabilidade pelo processo de decisão externo. Em outras palavras, a opinião pública gradualmente passa a ser incorporada por via de seus agentes como mídia, ONGs, partidos e lobbies na definição dos objetivos externos de um país. Paradoxalmente, isso tem trazido uma conseqüência inesperada na lógica da guerra, como anotado recentemente por Eric Hobsbawn: o soldado nega-se a morrer e aquele que deveria ser protegido pela ação e pelo sacrifício deste, a população civil, é quem mais está morrendo. "Na falta de uma autoridade global efetiva, conflitos armados no final do século 20 embaralharam a distinção entre combatentes e não-combatentes e fizeram dos civis as principais vítimas [...]. Por mais que seja verdade que o armamento de alta tecnologia tenha tornado possível em alguns casos restabelecer uma distinção entre alvos civis e militares e, portanto, entre combatentes e não-combatentes, não há razão para duvidar de que as principais vítimas da guerra continuarão a ser os civis" (HOBSBAWN, 2002).

Se os conflitos no Afeganistão demonstraram uma coisa é que o surgimento de um inimigo diluído e assimétrico diferente do tradicional ator estatal territorial não parece reverter essa tendência. $O$ paradoxo parece ser então que o aprofundamento da democracia diplomática (open diplomacy) nos países ocidentais tem um custo alto em vidas civis em outras latitudes do mundo.

Os ensaios de Abbas Amanat, Charles Hill e Nial Fergunson tratam do mundo árabe e, principalmente, das causas que vêm firmando o surgimento do fundamentalismo islâmico. Pouca novidade acrescentam em termos analíticos, mas constituem um valioso material de consulta na medida em que sistematizam argumentos que se popularizaram desde os atentados ao World Trade Center e ao Pentágono. Resumidamente esses argumentos são: primeiro, que as causas da emergência do fundamentalismo islâmico devem ser procuradas nas falhas da modernização do Oriente Médio como um todo. O resultado teria sido desemprego, aumento da violência e desarraigo cultural; segundo, que os grupos terroristas recrutam seus seguidores entre os deserdados da modernização, principalmente entre os jovens que passam a ter na leitura dogmática do Corão um pouco de alívio e esperança para suas desgraças materiais; terceiro, que a política equivocada dos Estados Unidos para a região especialmente em relação a Israel e a tolerância com o regime autoritário e corrupto da Arábia Saudita criaram grande resistência e ressentimento em relação ao Ocidente. E, finalmente, que a concorrência entre os dois principais países do Islã - a própria Arábia Saudita, de maioria sunita, e o Irã, de maioria xiita - financiam e exportam uma visão fundamentalista do Islã.

A maior novidade do argumento de Amanat é a tese de que a transformação fundamental que levou ao fortalecimento do extremismo islâmico "não foi deflagrada no mundo árabe mas pela revolução iraniana de 1979" (p. 49). Porém essa revolução não fez uma contribuição só pelo fato de afirmar uma retórica antiimperialista, que já existia e que a figura do Aiatolá Khomeini reforçaria até suas últimas conseqüências, e sim pela razão de que reforçou e deu uma nova arma de luta aos combatentes islâmicos na sua luta contra o adversário imperialista e seus representantes estatais na região: "Estabeleceu com firmeza ainda maior o apelo do paradigma do martírio" (p. 50; sem grifos no original). Essa descoberta tardia do martírio enquanto arma vem sendo percebida de maneira dramática no Ocidente, a tal ponto que alguns porta-vozes da mídia ocidental (o influente jornalista do The New York Times, Tomas Friedman, por exemplo) fazem de sua extinção um ponto-chave no confronto entre Ocidente e o extremismo islâmico. Sem entrar no mérito do dramatismo jornalístico, o que é bem certo no caso é que o horror que provoca no Ocidente o paradigma do martírio provém do fato de que sua maneira de produção não depende de investimentos financeiros maciços nem de tecnologia sofisticada. Como diria Weber, encontra sua produção, inserção e, portanto, sua legitimidade na mais profunda subjetividade do indivíduo. Da mesma forma, a emergência de um poder assimétrico, do qual tanto se fala hoje, não depende tanto de seu ator em si (as ONGs fundamentalistas ao estilo Al Qaeda), mas dos meios da violência utilizados e da possibilidade de generalização destes meios.

E ainda mais: a figura carismática do Aiatolá Khomeini conseguiu reverter a seu favor o discurso maniqueísta inserido na tradição política americana de que o mundo divide-se na luta entre as forças do bem e as forças do mal. O mais significativo nisso é que essa reversão das metáforas teológicas fez-se explorando elementos e falhas seculares da presença americana e de seus aliados na região. "Khomeini rotulou os Estados Unidos de Grande Satã por seu apoio aos poderes 'faraônicos' - uma referência ao xá e governantes conservadores dos demais países da região - e por reprimir os 'deserdados' da terra” (p. 49). Osama Bin Laden, profeta sem Estado, 
diferindo do Aiatolá iraniano, é o mais fiel e brilhante representante dos herdeiros do legado de Khomeini. Explora sem par o discurso da guerra santa dos fiéis contra os infiéis e utiliza com eficácia o poder assimétrico do martírio. Aliás, utiliza com eficácia os meios da globalização postos à disposição e estimulados pelos Estados Unidos.

Um dado curioso no âmbito acadêmico é que o 11 de setembro agudizou o pensamento de uma parte da comunidade científica das relações internacionais até o ponto (e aqui empresto uma frase de Norberto Bobbio escrita em relação a outro tema e em outro contexto) de começar a redescobrir o óbvio. É nessa linha de pensamento que se inscrevem os trabalho de Charles Hill e Nial Fergunson. Ambos os autores descobrem que a reação americana aos ataques do 11 setembro não formava parte da deflagração de uma "uma nova guerra", como a equipe de ideólogos do staff externo de Washington definem-na. Hill chega a dizer que a guerra contra o terrorismo é uma guerra que se desenvolve desde os anos setenta, em duas etapas. "A primeira começou na década de setenta [...]. Os terroristas, nessa primeira guerra eram motivados basicamente por razões políticas" (p. 95, 97). Era esse o caso de atos da Organização para Libertação da Palestina (OLP) que procuravam destruir o Estado de Israel. A segunda fase dessa guerra começou nos anos 90 com o primeiro ataque ao World Trade Center e a explosão de bombas nas embaixadas americanas no Quênia e na Tanzânia. Coincidindo com esse argumento Fergunson afirma que, "Se pararmos para refletir, veremos que há precedentes para quase todos os elementos dos ataques do 11 de setembro" (p. 124). Fergunson acredita que a causa mais profunda dessa nova guerra é a emergência de uma "religião política dinâmica perigosa", que desafia um império maduro como os Estados Unidos (p. 140)

A pergunta que surge aqui é quase obrigatória: por que essa guerra e suas causas só foram descobertas agora? Diríamos que essa guerra (ou nova fase da guerra) não era um processo tão alarmante porque suas fontes principais eram unidades políticas territoriais como Líbia, Síria, Iraque, ou uma organização pretendente a um Estado palestino como a OLP: como inimigos tangíveis e territoriais podiam ser destruídos. Ora, não é suficiente o argumento do surgimento do inimigo diluído, invisível e de organização descentralizada que é o terrorismo de ONGs fundamentalistas do tipo Al Qaeda para descobrir-se com grande alarme a potencialidade devastadora de suas ações. Aliás, para toda a comunidade científica das relações internacionais poderia ter passado despercebido esse fato - exceto para Samuel Huntington, como todos nós já sabemos hoje. Coincidindo ou não com suas teses culturalistas da política internacional pós-Guerra Fria, não existe nenhuma dúvida de que o autor de $O$ choque de civilizações (HUNTINGTON, 1997) já previa que os elementos culturais (tais como a religião) podiam substituir os conflitos ideológicos como elementos da nova dinâmica do poder mundial. Uma leitura atenta de Huntington por parte de autores como Hill e Fergunson levá-los-ia a uma nova “descoberta do óbvio". E é exatamente o inteligente pensador do choque de civilizações quem novamente e, dessa vez no balanço que faz dos acontecimentos do 11 de setembro, que nos traz luzes e responde de maneira clara à pergunta de início de parágrafo: a questão fundamental é que "A era das guerras muçulmanas tem chegado a casa (América)" (HUNTINGTON, 2001-2002, p. 11.). Esse é o fato relevante: a "redescoberta" ocorre porque as guerras que confrontam atores estatais em torno de motivações seculares e não-seculares são descobertas com dramatismo quando elas atingem o solo e os símbolos do poderio do maior império desde o tempos de Roma.

Não se questiona que os autores da obra que resenhamos ocupem-se de tão relevante problema para as relações internacionais. No final das contas trata-se do futuro do number one do sistema internacional contemporâneo. Porém, retardatários nas suas descobertas, fica para esses autores o recurso cômodo da polêmica com o também redescoberto e lúcido Huntington. É esse o recurso de Fergunson, para quem "O que estamos presenciando, portanto, é não um choque de civilizações, mas uma colisão entre um império maduro e uma religião política dinâmica e perigosa, em um mundo que é tão faccioso em termos políticos quanto é integrado no âmbito econômico" (p. 140).

Concluindo, podemos assinalar que, do conjunto de trabalhos e autores resenhados, suas tentativas de explicação macropolíticas são relativamente decepcionantes, posto que não consideram três elementos fundamentais nas suas análises, dois deles políticos e um outro civilizacional. Em primeiro lugar, quais são os meios viáveis, supondo que estamos mesmo numa situação de guerra, que poderão conter a autonomia de ação dos grupos terroristas? Por que a autonomia e descentralização de atuação parece ser o grande problema em relação a esses grupos? No passado grupos como Al Queda, Hamas e Yizbollah escaparam do controle dos Estados Unidos e Israel, países que contribuíram para sua criação e sustentação no final da Guerra Fria. No presente escapam do controle da Autoridade Nacional Palestina de Arafat, do governo de Beirute, da Síria e da 
Líbia. Nesse sentido resulta irônico que os Estados Unidos e Israel peçam para Arafat o que eles não puderam fazer no passado não muito distante com Osama Bin Laden: o controle da ação dos grupos extremistas.

Em segundo lugar, nenhum deles aponta que a grande potência americana está presa a um recurso que era eficaz no tempo das polarizações ideológicas Leste-Oeste. Nos tempos da Guerra Fria era possível negociar vantagens econômicas e políticas entre atores estatais assimétricos em troca de vantagens estratégicas. Assim o ator de maior poder ganhava uma vantagem estratégica ou geopolítica e concedia em compensação uma vantagem política ou econômica ao ator de menor recurso de poder. Um dos problemas mais sérios que se apresentam para a hegemonia americana no Oriente Médio é como negociar vantagens estratégicas com países de conhecido autoritarismo como Arábia Saudita ou com democracias como Israel, consentindo com uma crescente prática de intolerância em matéria de direitos humanos - o que viola o próprio fundamento valorativo da política externa americana, voltada desde sua fundação como federação para a promoção e o apostolado da democracia e dos direitos humanos no mundo. Quais são os custos políticos da vantagem estratégica de contar com uma base militar na Arábia Saudita quando é vox populi no Oriente Médio que a casa dos Saud promovem e financiam a versão extremista de grupos fundamentalistas do islamismo político sunita? A médio e longo prazo o silêncio americano não será funcional ao novo inimigo político que diz combater.

Em terceiro lugar, nenhum dos autores estudados passa revista a um problema civilizacional da maior importância: é possível secularizar as crenças e os mitos religiosos? E quais são os meios para isso? A história do Ocidente mostra que isso é possível. A Paz de Westfália (1648) significou o ato fundador do moderno sistema de estados (ao reconhecer o princípio de soberania e de não-intervenção entre os estados), mas também significou o começo da secularização dos princípios religiosos. Isto é, da subordinação dos dogmas religiosos aos valores políticos e da coexistência pacífica desses valores entre as nações européias. Antes da data simbólica e histórica de 1648 o Ocidente não era mais civilizado que os combatentes fervorosos da $\mathrm{Al}$ Qaeda. A guerra religiosa dos trinta anos entre estados europeus (1618-1648) foi um dos piores momentos de barbárie que a história humana conhece. Entretanto, um acelerado processo de secularização histórico permitiu domesticar os instintos de destruição dos povos ocidentais europeus. Dito de outra maneira, mesmo que se inicie um processo acelerado de modernização material no Oriente Médio e em outros lugares da Ásia, África e América Latina, um projeto de construção de paz internacional duradoura estaria incompleto sem atingir o estágio em que a tolerância aparece como um processo secularizado. A experiência da Europa Ocidental demonstra que é possível universalizar esse processo ainda parcial de secularização da tolerância.

Para encerrar, qual é o papel das relações internacionais na construção normativa desses processos? A leitura do livro $A$ era do terror deixa-nos um pouco pessimistas, por um mal generalizado do quadro epistêmico dessa área do conhecimento no âmbito global. Se a comunidade brasileira das relações internacionais (entre os quais me incluo, of course) mostrou pouca imaginação e originalidade nas análise ex post facto do 11 de setembro, então o único consolo é que, com a honrosa exceção, pre facto, diga-se de passagem, de Huntington, a comunidade acadêmica internacional igualou-se em explicações e análises genéricas às nossas. No final uma constatação melancólica: faltou imaginação para ambas as comunidades epistêmicas.

Recebido em 4 de maio de 2002. Aprovado em 19 de maio de 2002.

Rafael Villa (rafael.villa@terra.com.br) é Doutor em Ciência Política pela Universidade de São Paulo (USP) e Professor do Departamento de Ciência Política da USP.

\section{REFERÊNCIASBIBLIOGRÁFICAS}

HOBSBAWN, E. 2002. A epidemia da guerra. Folha de S. Paulo, 14.abr, caderno Mais!, p. 4-10.

HUNTINGTON, S. 1997. O choque de civilizações. Rio de Janeiro : Campus.

.2001-2002. The Age of Muslim Wars. Newsweek, Washington, p. 6-13, Dec.-Feb. Special Davos Edition.

KENNEDY, P. 1989. Ascensão e queda das grandes potências. Rio de Janeiro : Campus. 